\title{
Improved amorphous/crystalline silicon interface passivation by hydrogen plasma treatment
}

\author{
A. Descoeudres, ${ }^{1, a)}$ L. Barraud, ${ }^{1}$ Stefaan De Wolf, ${ }^{1}$ B. Strahm, ${ }^{2}$ D. Lachenal, ${ }^{2}$ C. Guérin, ${ }^{2}$ \\ Z. C. Holman, ${ }^{1}$ F. Zicarelli, ${ }^{1}$ B. Demaurex,${ }^{1}$ J. Seif, ${ }^{1}$ J. Holovsky, ${ }^{3}$ and C. Ballif ${ }^{1}$ \\ ${ }^{1}$ Photovoltaics and Thin Film Electronics Laboratory, Institute of Microengineering (IMT), Ecole \\ Polytechnique Fédérale de Lausanne (EPFL), Rue A.-L. Breguet 2, 2000 Neuchâtel, Switzerland \\ ${ }^{2}$ Roth \& Rau Switzerland SA, Rue de la Maladière 23, 2000 Neuchâtel, Switzerland \\ ${ }^{3}$ Institute of Physics, Academy of Sciences of the Czech Republic, Cukrovarnicka 10, 16253 Prague 6, \\ Czech Republic
}

(Received 10 August 2011; accepted 31 August 2011; published online 23 September 2011)

\begin{abstract}
Silicon heterojunction solar cells have high open-circuit voltages thanks to excellent passivation of the wafer surfaces by thin intrinsic amorphous silicon (a-Si:H) layers deposited by plasma-enhanced chemical vapor deposition. We show a dramatic improvement in passivation when $\mathrm{H}_{2}$ plasma treatments are used during film deposition. Although the bulk of the a-Si:H layers is slightly more disordered after $\mathrm{H}_{2}$ treatment, the hydrogenation of the wafer/film interface is nevertheless improved with as-deposited layers. Employing $\mathrm{H}_{2}$ treatments, $4 \mathrm{~cm}^{2}$ heterojunction solar cells were produced with industry-compatible processes, yielding open-circuit voltages up to $725 \mathrm{mV}$ and aperture area efficiencies up to 21\%. (C) 2011 American Institute of Physics. [doi:10.1063/1.3641899]
\end{abstract}

Among high-efficiency devices, silicon heterojunction solar cells stand out for their high performance and potential for low production cost. Conversion efficiencies of $23 \%$ and open-circuit voltages up to $743 \mathrm{mV}$ on thin wafers have been demonstrated. ${ }^{1}$ Passivation of the crystalline silicon (c-Si) wafer surfaces is achieved with very thin intrinsic hydrogenated amorphous silicon (a-Si:H) layers, deposited by plasmaenhanced chemical vapor deposition (PECVD) or similar methods. The emitter and back surface field of the cell are formed with either PECVD doped a-Si:H or doped microcrystalline silicon layers. The simple structure of these cells requires only low-temperature processes that are already used at the industrial scale.

To achieve high open-circuit voltage and, therefore, high efficiency, the passivation of the wafer surfaces by the thin intrinsic a-Si:H layers has to be as good as possible. An a-Si:H layer passivates a c-Si surface mainly by hydrogenation of the silicon dangling bonds, leading to a reduction of the interface defect density. ${ }^{2}$ It has been shown for both thin film silicon solar cells $^{3}$ and c-Si wafer passivation ${ }^{4}$ that device-grade a-Si:H material is produced from deposition regimes close to the crystalline transition. This can be achieved by using highly diluted or highly depleted silane plasmas, for example. When depositing on c-Si substrates, however, epitaxial growth has to be avoided because of its detrimental effect to passivation. ${ }^{5}$ Consequently, the amorphous-to-crystalline transition must be approached with caution when depositing on wafers. In this study, we used highly depleted silane plasmas. ${ }^{4}$ To come closer to this transition without risking epitaxial growth, we tested hydrogen $\left(\mathrm{H}_{2}\right)$ plasma treatments during a-Si:H growth via brief interruptions of deposition. It is known that such treatments can lead to complete crystallization of a-Si: $\mathrm{H}$, due to removal of strained bonds from the a-Si:H growth surface by $\mathrm{H}$ atoms. ${ }^{6,7} \mathrm{We}$ anticipate an increased passivation level as the a-Si:H is further pushed towards the amorphous-to-crystalline transition.

${ }^{a)}$ Electronic mail: antoine.descoeudres@epfl.ch.
Amorphous silicon layers were deposited at $200^{\circ} \mathrm{C}$ in two different automated parallel-plate PECVD reactors. The first is a multi-chamber variable frequency reactor by INDEOtec with the following specifications: $15 \times 16 \mathrm{~cm}^{2}$ electrode size, $15 \mathrm{~mm}$ gap, and radio frequency (RF) excitation (13.56 MHz). The second reactor is a modified version of a large-area industrial KAIM PlasmaBox ${ }^{\mathrm{TM}}$ reactor $^{8}$ with the following specifications: $50 \times 60 \mathrm{~cm}^{2}$ electrode size, $13 \mathrm{~mm}$ gap, very high frequency (VHF) excitation (40.68 MHz). Float zone (FZ) $n$-type c-Si wafers $(4 \Omega \cdot \mathrm{cm})$ were used as substrates, either with (100) or (111) polished surfaces (wafer thickness $300 \mu \mathrm{m}$ ), or with textured surfaces on which (111) faces were revealed (wafer thickness $230 \mu \mathrm{m}$ ). Just before deposition, the native oxide on the wafer surfaces was removed in a hydrofluoric acid solution. After deposition, effective minority carrier lifetimes were measured with a Sinton Consulting WCT-100 quasi-steady-state photoconductance system. ${ }^{9}$ In addition, a-Si:H films were also characterized $e x$-situ by spectroscopic ellipsometry and by attenuated total reflectance Fourier transform infrared (ATR-FTIR) spectroscopy. Details about the structure and fabrication process of complete heterojunction solar cells are described elsewhere. ${ }^{4}$

To investigate the effect of $\mathrm{H}_{2}$ treatment on the passivating intrinsic layers, two deposition sequences were tested, as shown in Figure 1. The first consisted of a single step of pure silane plasma; the second consisted of three shorter silane plasma steps (same conditions as for the first deposition type) with an additional short $\mathrm{H}_{2}$ plasma step after each silane step. The durations of the discharges were chosen to deposit a total a-Si:H film thickness of $15 \mathrm{~nm}$ in both cases.

Figure 2 gives the effective lifetimes of (100) and (111) c-Si wafers passivated with untreated and treated a-Si:H layers before and during annealing. Annealing reveals important information about the physics of passivation (for example movement of hydrogen in the film and at the interface), and it is also necessary during solar cell fabrication to cure contact metal paste. (111) surfaces are generally easier to passivate, likely because each silicon atom at the (111) surface has only one dangling 
(a)
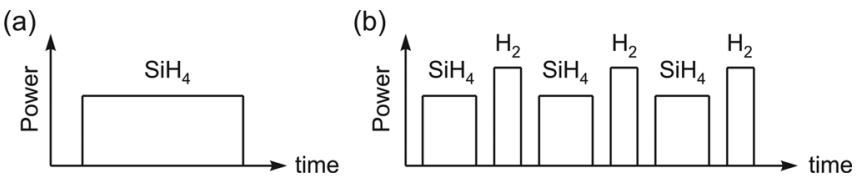

FIG. 1. Schematic representation of the deposition sequences: (a) single silane plasma step; (b) deposition split into three shorter silane plasma steps, alternating with $\mathrm{H}_{2}$ plasma treatments.

bond, allowing for ideal monohydride termination. ${ }^{10}$ By contrast, there are two dangling bonds per atom on (100) surfaces, potentially leading to more complex surface hydrogenation..$^{11,12}$ This may explain the higher lifetimes measured on (111) wafers for both kinds of a-Si:H layers. Hydrogen treatment is clearly beneficial, both before and after annealing: the lifetimes values are roughly doubled on (111) wafers when $\mathrm{H}_{2}$ treatment is used, the improvement is less pronounced on (100) wafers but still visible. Upon annealing, all samples show a fast initial improvement in passivation, attributed to hydrogen reorganization at the $\mathrm{a}-\mathrm{Si} \mathrm{H} / \mathrm{c}-\mathrm{Si}$ interface (migration from the bulk to the interface). ${ }^{13,14}$ Such improvement indicates also that the deposited layers are relatively disordered. ${ }^{13}$ After this large initial improvement, the lifetime obtained with the treated layers shows a rapid saturation followed by a slight decrease after roughly $10 \mathrm{~min}$. On the other hand, samples passivated with untreated layers show constant improvement, at least during the time range explored here. Apparently, the a-Si:H/c-Si interface is well hydrogenated and passivated by as-deposited treated layers, whereas, with untreated layers, hydrogen may diffuse more slowly from the a-Si:H bulk to the interface during annealing. Indeed, Schulze et al. ${ }^{14}$ suggested that the as-deposited interface defect density is determined by the local network structure at the a-Si:H/c-Si interface, while the interface defect density after annealing is determined more by the bulk properties of the film, due to subsequent hydrogen equilibration. ${ }^{14}$ In agreement with this hypothesis, we observed that a single $\mathrm{H}_{2}$ plasma treatment step (after the first silane plasma) gives similar

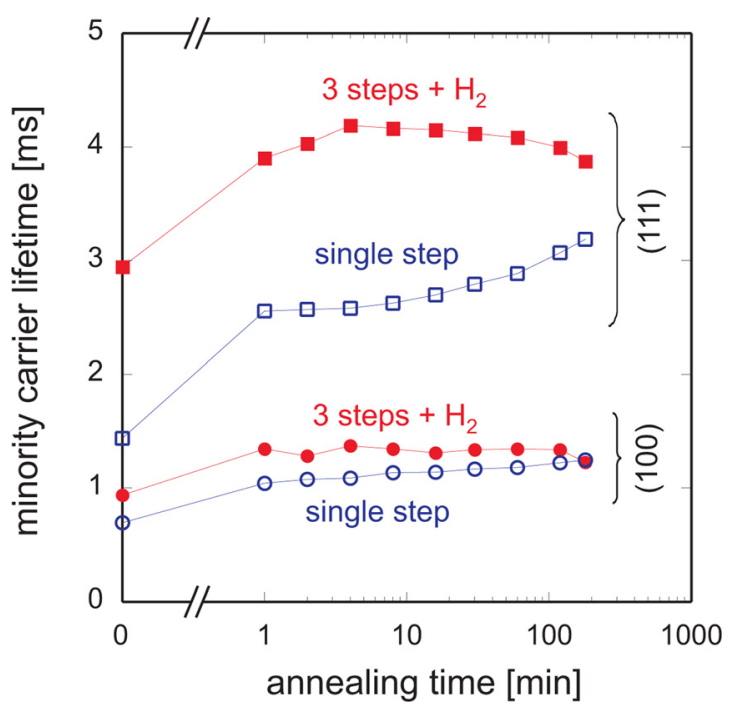

FIG. 2. (Color online) Evolution of the minority carrier effective lifetime during annealing at $190^{\circ} \mathrm{C}$ in air. Polished (100) and (111) c-Si wafers were passivated on both sides with $15 \mathrm{~nm}$ intrinsic a-Si:H layers co-deposited (VHF PECVD) with the sequences illustrated in Figure 1. Lifetime values were measured at an excess carrier density of $10^{15} \mathrm{~cm}^{-3}$. Lines are guides for the eye. as-deposited effective lifetimes as three treatment steps. This underlines that the as-deposited a-Si:H/c-Si interface passivation is mainly determined by $\mathrm{H}_{2}$ treatments in its vicinity.

Infrared spectroscopy of the treated and untreated a$\mathrm{Si}: \mathrm{H}$ layers shows significant differences in silicon-hydrogen bonding. Absorbance spectra of layers deposited on (111) polished c-Si wafers are given in Figure 3, in a spectral region where peaks from monohydride $(\mathrm{SiH})$ bonds and higher hydrides $\left(\mathrm{SiH}_{2}\right)$ bonds are present (stretching modes). ${ }^{15-18}$ The spectra of layers deposited on (100) wafers are identical to those on (111) surfaces (not shown), indicating that the crystal orientation has minor influence on the bulk layer properties. The hydrogen content in the layer clearly increases when $\mathrm{H}_{2}$ treatment is used, since the total area under the $\mathrm{SiH}$ and $\mathrm{SiH}_{2}$ peaks is larger (both layers have the same thickness, verified by ellipsometry). ${ }^{16}$ The ratio of the $\mathrm{SiH}_{2}$ peak area to the $\mathrm{SiH}$ peak area increases with the treatment, indicating that the treated a-Si:H matrix is more disordered and contains more voids than the untreated layer. ${ }^{15}$ This might seem contradictory to the general aim of this study, namely an improvement in a-Si:H material quality by approaching the crystallization transition via $\mathrm{H}_{2}$ treatment. However, the presence of more hydrogen could be a signature that layers are close to the crystalline transition. It has indeed been shown that the hydrogen content in a-Si:H reaches its maximum value at the transition (obtained by $\mathrm{H}_{2}$ dilution), ${ }^{19}$ and that disorder in a-Si:H also increases close to the transition. ${ }^{20}$ This increase in disorder might explain the difference in behavior of wafers passivated with treated and untreated a-Si:H layers during annealing (see Figure 2). If the passivation level after prolonged annealing is determined by the bulk properties of the film, ${ }^{14}$ the slight decrease in passivation observed after 10 min with treated layers may reflect their increased disorder. Nevertheless, even if the as-deposited state is not an equilibrium state, the gain in lifetime obtained with $\mathrm{H}_{2}$ treatments due to the initial good hydrogenation of the interface is really significant. Globally, this treatment-induced improvement is largely dominating an eventual degradation caused by the bulk disorder if

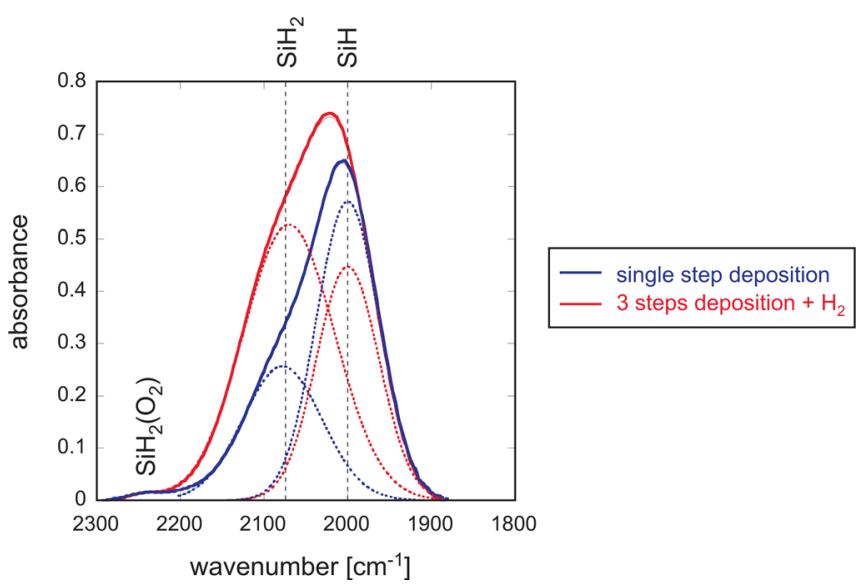

FIG. 3. (Color online) Absorbance spectra of $15 \mathrm{~nm}$ thick treated and untreated a-Si:H layers (see Figure 1) deposited on (111) c-Si wafers measured by ATR-FTIR. Spectra were deconvoluted with two gaussians, centered at $2000 \mathrm{~cm}^{-1}$ (monohydride bonds, stretching mode) and at $2080 \mathrm{~cm}^{-1}$ (higher hydrides bonds, stretching mode). The small oxide peak at 2250 $\mathrm{cm}^{-1}$ is due to film oxidation. 


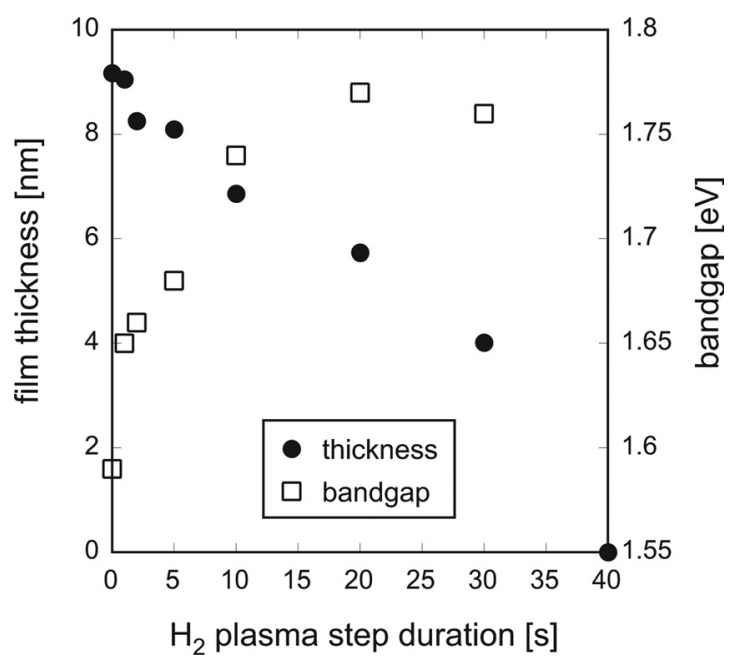

FIG. 4. Effect of $\mathrm{H}_{2}$ plasma treatment duration on a-Si:H film thickness and bandgap, measured with spectroscopic ellipsometry. Intrinsic a-Si:H was deposited (RF PECVD) in six steps with $\mathrm{H}_{2}$ treatment after each step. The duration of the deposition steps was the same for all samples; the duration of the $\mathrm{H}_{2}$ treatments was varied.

reasonable annealing times are used, as it is the case in the actual device fabrication process.

Increased disorder of the a-Si:H material due to $\mathrm{H}_{2}$ treatment is also observed with spectroscopic ellipsometry measurements. By fitting data with the Tauc-Lorentz model, ${ }^{21}$ we found that the broadening parameter $C$, which is related to material disorder, increases slightly from 2 to $2.15 \mathrm{eV}$ when $\mathrm{H}_{2}$ treatment is applied. Hydrogen treatment also increases the bandgap of the a-Si:H material, measured with ellipsometry. The bandgap typically increases from 1.6 to $1.75 \mathrm{eV}$, but it can be tuned between these two values depending on the treatment duration, as shown in Figure 4. The opening of the bandgap confirms that more hydrogen is incorporated in the aSi:H layer. ${ }^{22}$ Schulze et $a .^{22}$ have observed that hydrogeninduced bandgap widening of a-Si:H mainly causes an increase in the valence band offset at the a-Si:H/c-Si interface, ${ }^{22}$ which may modify hole transport in devices. Figure 4 also shows that the $\mathrm{H}_{2}$ plasma has an etching effect. By increasing the treatment duration and keeping the deposition time constant, the final film thickness monotonically decreases to zero. Thus, the treatment parameters have to be chosen carefully. Notably, it has been reported that the hydrogen content in a-Si:H might be higher within a few nanometers of the a-Si:H/c-Si interface, leading to a higher bandgap if ultra-thin layers are deposited. ${ }^{18,23}$ In our case, an increase in bandgap with $\mathrm{H}_{2}$ treatment is also observed when the film thickness is kept constant at $10 \mathrm{~nm}$ (not shown). Consequently, the effect is linked to the treatment and not to thickness-related causes.

Based on the results presented above, we optimized deposition conditions and treatment parameters to improve the passivation level. Carrier lifetimes up to $11.2 \mathrm{~ms}$ and $7.2 \mathrm{~ms}$ have been obtained on polished and textured wafers, respectively, with as-deposited a-Si:H layers as thin as $12 \mathrm{~nm}$. On solar cell precursors (textured wafers passivated with $\sim 15 \mathrm{~nm}$ in and ip stacks), lifetimes up to $8.3 \mathrm{~ms}$ were measured as-deposited, giving a so-called implied open-circuit voltage of $734 \mathrm{mV}$. The parameters of the best heterojunction solar cells produced with RF and VHF PECVD are given in Table I. The level of
TABLE I. Illuminated IV parameters (open-circuit voltage, $V_{\text {oc }}$; shortcircuit current density, $J_{\text {sc }}$; and fill factor, FF) of the best $2 \times 2 \mathrm{~cm}^{2}$ heterojunction solar cells obtained with RF and VHF PECVD from textured wafers, measured under standard test conditions (AM-1.5G, $25^{\circ} \mathrm{C}$, in-house measurement).

\begin{tabular}{lllll}
\hline \hline PECVD & $V_{\text {oc }}[\mathrm{mV}]$ & $J_{\text {sc }}\left[\mathrm{mA} / \mathrm{cm}^{2}\right]$ & FF [\%] & efficiency [\%] \\
\hline RF & 724 & 37.0 & 76.9 & 20.6 \\
VHF & 725 & 37.3 & 77.8 & 21.0 \\
\hline \hline
\end{tabular}

passivation is comparable with both PECVD frequencies. Thanks to the excellent passivation obtained using $\mathrm{H}_{2}$ treatments, $21 \%$ aperture area efficiency is reached on $4 \mathrm{~cm}^{2}$ cells.

In summary, the quality of intrinsic a-Si:H layers used for c-Si wafer passivation can be modified and improved by $\mathrm{H}_{2}$ plasma treatment during layer growth, without risking epitaxial growth. By going closer to the amorphous-to-crystalline transition, as-deposited $\mathrm{H}_{2}$ treated a-Si:H layers better hydrogenate the wafer/film interface. The bulk of treated films is, however, slightly more disordered due to an increase in the hydrogen content, which might lead to reduced lifetime after excessive annealing. Medium-sized silicon heterojunction solar cells with screen-printed contacts were optimized using this approach, yielding $21 \%$ aperture area efficiencies.

The authors acknowledge Y. Andrault for wafer preparation and $\mathrm{P}$. Bôle Rothen for support. This work was supported by the Axpo Naturstrom Fonds and by the European Commission (FP7 project 20pl $\mu$ s, Grant No. 256695).

${ }^{1}$ T. Mishima, M. Taguchi, H. Sakata, and E. Maruyama, Sol. Energy Mater. Sol. Cells 95, 18 (2011).

${ }^{2}$ J. Pankove and M. Tarng, Appl. Phys. Lett. 34, 156 (1979).

${ }^{3}$ J. Koh, Y. Lee, H. Fujiwara, C. R. Wronski, and R. W. Collins, Appl. Phys. Lett. 73, 1526 (1998).

${ }^{4}$ A. Descoeudres, L. Barraud, R. Bartlome, G. Choong, S. De Wolf, F. Zicarelli, and C. Ballif, Appl. Phys. Lett. 97, 183505 (2010).

${ }^{5}$ S. De Wolf and M. Kondo, Appl. Phys. Lett. 90, 042111 (2007).

${ }^{6}$ J. J. Boland and G. N. Parsons, Science 256, 1304 (1992).

${ }^{7}$ S. Sriraman, S. Agarwal, E. S. Aydil, and D. Maroudas, Nature 418, 62 (2002).

${ }^{8}$ J. Perrin, J. Schmitt, C. Hollenstein, A. A. Howling, and L. Sansonnens, Plasma Phys. Controlled Fusion 42, B353 (2000).

${ }^{9}$ R. Sinton and A. Cuevas, Appl. Phys. Lett. 69, 2510 (1996).

${ }^{10}$ G. S. Higashi, Y. J. Chabal, G. W. Trucks, and K. Raghavachari, Appl. Phys. Lett. 56, 656 (1990).

${ }^{11}$ T. Sakurai and H. D. Hagstrum, Phys. Rev. B 14, 1593 (1976).

${ }^{12}$ S. De Wolf, B. Demaurex, A. Descoeudres, and C. Ballif, Phys. Rev. B 83, 233301 (2011).

${ }^{13}$ S. De Wolf, S. Olibet, and C. Ballif, Appl. Phys. Lett. 93, 032101 (2008).

${ }^{14}$ T. F. Schulze, H. N. Beushausen, C. Leendertz, A. Dobrich, B. Rech, and L. Korte, Appl. Phys. Lett. 96, 252102 (2010).

${ }^{15}$ J. C. Knights, G. Lucovsky, and R. J. Nemanich, J. Non-Cryst. Solids 32, 393 (1979).

${ }^{16}$ A. A. Langford, M. L. Fleet, B. P. Nelson, W. A. Lanford, and N. Maley, Phys. Rev. B 45, 13367 (1992).

${ }^{17}$ A. H. M. Smets, W. M. M. Kessels, and M. C. M. van de Sanden, Appl. Phys. Lett. 82, 1547 (2003).

${ }^{18}$ H. Fujiwara and M. Kondo, Appl. Phys. Lett. 86, 032112 (2005).

${ }^{19}$ U. Kroll, J. Meier, A. Shah, S. Mikhailov, and J. Weber, J. Appl. Phys. 80, 4971 (1996).

${ }^{20}$ P. Roca i Cabarrocas, J. Non-Cryst. Solids 266-269, 31 (2000).

${ }^{21}$ G. E. Jellison and F. A. Modine, Appl. Phys. Lett. 69, 371 (1996).

${ }^{22}$ T. F. Schulze, L. Korte, F. Ruske, and B. Rech, Phys. Rev. B 83, 165314 (2011).

${ }^{23}$ P. J. van den Oever, M. C. M. van de Sanden, and W. M. M. Kessels, J. Appl. Phys. 101, 123529 (2007). 